\title{
SCNH2 is a novel apelinergic family member acting as a potent mitogenic and chemotactic factor for both endothelial and epithelial cells*
}

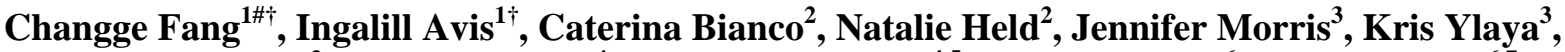 \\ Stephen M. Hewitt ${ }^{3}$, Alfred C. Aplin ${ }^{4}$, Roberto F. Nicosia ${ }^{4,5}$, Laura A. Fung ${ }^{6}$, John D. Lewis ${ }^{6,7}$, \\ William G. Stetler-Stevenson ${ }^{8}$, David S. Salomon ${ }^{2}$, Frank Cuttitta ${ }^{1}$

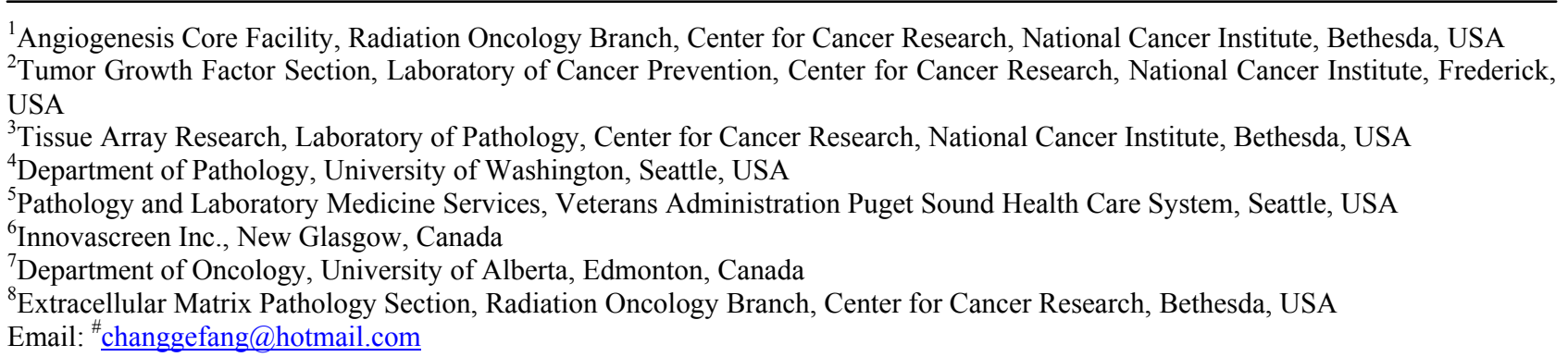

Received 18 January 2013; revised 22 February 2013; accepted 7 March 2013

Copyright (C) 2013 Changge Fang et al. This is an open access article distributed under the Creative Commons Attribution License, which permits unrestricted use, distribution, and reproduction in any medium, provided the original work is properly cited.

\begin{abstract}
The gut hormone apelin is a major therapeutic focus for several diseases involving inflammation and aberrant cell growth. We investigated whether apelin-36 contained alternative bioactive peptides associated with normal physiology or disease. Amino acid sequence analysis of apelin-36 identified an amidation motif consistent with the formation of a secondary bioactive peptide (SCNH2). SCNH2 is proven to be mitogenic and chemotactic in normal/malignant cells and augments angiogenesis via a PTX-resistant/CT$\mathrm{X}$-sensitive $\mathrm{G}$ protein-coupled receptor (GPCR). Notably, SCNH2 is substantially more potent and sensitive than apelin-13 and vascular endothelial growth factor-A. Endogenous SCNH2 is highly expressed in human tumors and placenta and in mouse embryonic tissues. Our findings demonstrate that SCNH2 is a new apelinergic member with critical pluripotent roles in angiogenesis related diseases and embryogenesis via a non-APJ GPCR.
\end{abstract}

Keywords: Novel Apelinergic Member; SCNH2;

\footnotetext{
${ }^{*}$ The authors declare no competing financial interests.

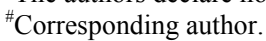

Current address, Advanced Personalized Diagnostics, LLC, 6006 Bangor Drive, Alexandria, USA.

${ }^{+}$These authors contributed equally to this work.
}

Angiogenesis; Migration; Embryogenesis

\section{INTRODUCTION}

Apelin-13 (APL-13) is a gastrointestinal tract peptide that regulates a variety of physiological functions via its interaction with the APJ receptor [1-3]. APL-13 is derived from a 77 amino acid preprohormone, which is enzymatically processed into apelin-36 (APL-36), apelin-17, and apelin-16, prior to being converted to its final modified state [2]. Its amino acid structure is highly conserved in vertebrate species. APL-13 expression is augmented under hypoxic conditions and has been shown to block HIV cell infection, controls the pathophysiology of both metabolic and cardiovascular diseases, activates neuron signaling, stimulates epithelial cell growth, modulates angiogenesis, underlies tip ce11/stalk cell communication, and normalizes tumor vasculature [2,4-8]. As with any other bioactive peptide, alternate processing events may be involved with the translated protein product of the apelin gene.

Peptide amidation selectively tracks with biological activity and involves consecutive enzymatic processing events that target a recognizable amino acid motif within the precursor molecule [9-11]. We have identified a classic peptide amidation motif (GRRK or GRKK) within the APL-36 prohormone that encodes for a carboxy-terminal (C-terminal) glycine amide and is highly con- 
served in mammalian/marsupial species but is not found in lower vertebrates. The human peptide, denoted as "selective apl-36 cutting and amidation" peptide ( $\mathrm{SCNH} 2$ ), has a predicted amino acid sequence of L-V-Q-P-R-GS-R-N-G-P-G-P-W-Q-G-NH2.

Given that other peptide amides, such as adrenomedullin (AM), are proven mitogenic factors and have alternative $\mathrm{C}$-terminal derivatives with either low or absent bioactivity [12-16], $\mathrm{SCNH} 2$ (amide), $\mathrm{SCOH}$ (free-acid) and SCGly (glycine-extended intermediate) peptides were synthesized to evaluate their effects on cell proliferation. Only the peptide amide derivative proved to be bioactive. Accordingly, we evaluated whether $\mathrm{SCNH} 2$ is involved in tumor angiogenesis and metastasis using tumor and endothelial cell proliferation, migration, and in vitro/in vivo angiogenesis assays. In addition, selected SM inhibitors blocked SCNH2 activated phosphorylation of PI3/Akt and p44/42 MAPK signaling pathways as well as that of APL-13 [17,18]. Using a specifically designed fluorescent activated cell-sorting (FACS) assay, we enriched the $\mathrm{SCNH} 2$ receptor positive cells from a human breast carcinoma cell line (MB435). Importantly, using a CTX/PTX sensitivity assay, the SCNH2 putative receptor was characterized as a CTX-sensitive and PT$\mathrm{X}$-resistant $\mathrm{G}$ protein-coupled receptor, which is distinctly different from the APL-13 receptor, APJ receptor, because the latter is a PTX-sensitive G protein-coupled protein [19]. Finally, using a specifically developed hyperimmune rabbit anti-SCNH2 $\operatorname{IgG}$ (IgGHIRS) in an immunohistochemical (IHC) staining, we demonstrated that the anatomical endogenous $\mathrm{SCNH} 2$ on the mouse embryonic E17 tissue, human normal tissues, and tumor tissue array, in which the augmented $\mathrm{SCNH} 2$ expression suggests that $\mathrm{SCNH} 2$ may play certain major roles in embryogenesis and carcinogenesis.

\section{MATERIALS AND METHODS}

\subsection{Reagents and Cell Lines}

$\mathrm{SCOH}$, SCGly, and SCNH2 were synthesized by GenScript; biotinylated SCNH2 (bSCNH2) were synthesized by Princeton BioMolecules; gastrin-releasing peptide (GRP), adrenomedullin (AM), APL-36, APL-13, luteinizing hormone-releasing hormone (LHRH), arginine vasopressin (AVP) and oxytocin (OXT) were purchased from Bachem, and vascular endothelial growth factor A (VEGF-A) was obtained from the R\&D Systems; LY2228820, LY294002, U01216, AMD3100, and PTX were purchased from Sigma-Aldrich; normal rabbit IgG (IgGNRS) and IgGHIRS were produced by Epitomics; the anti-APJ receptor antibody was purchased from Santa Cruz; the human umbilical vein endothelial cell line (HUVEC) was purchased from Lonza; HMEC-1s was authorized by the Centers of Disease Control and Pre- vention; the immortalized porcine aortic endothelial cell line (PAE) was agift from Dr. C.H. Heldin, Sweden; the immortalized human mast cell line (HMC-1) was kindly provided by Dr. J. H. (Butterfield, MN, USA); the human ocular melanoma (92.1) was a gift of Dr. Libutti, (NCI). The rest of the cell lines were acquired from the ATCC. An official NCI/MTA was obtained for the acquisition of all cell lines.

\subsection{Proliferation Assay}

The ATPlite one-step firefly luciferase assay (PerkinElmer) was used for all cell proliferation studies. In short, 1250 cells were seeded at a volume of $50 \mu \mathrm{l}$ per well in appropriate media containing $0.5 \%$ FBS in a white wall 96-well plate with a clear bottom (Costar 3610). Following overnight incubation, the peptide was added to the each well to obtain a final volume of $100 \mu \mathrm{l}$ and the cells were incubated for 3 - 5 days at $37^{\circ} \mathrm{C} / 5 \% \mathrm{CO}_{2}$ and terminated according to the company protocol.

\subsection{ELISA, Purification and Absorbed Antibody Assays}

ELISA assays were a modification of our previously used RIA [16]. Target peptides were passively absorbed to 96-well PVC plates (BD Falcon) at $100 \mathrm{ng} / \mathrm{well}$ and subsequently blocked with $1 \%$ BSA/PBS (Sigma-Aldrich). Serial dilutions of respective IgGNRS or IgGHIRS were added to target peptide plates, incubated at room temperature and washed $3 \mathrm{x}$ in PBS. The bound antibody detected with 1:500 goat anti-rabbit IgG-HRP (Santa Cruz), followed by stabilized TMB chromogen (Invitrogen), blue > yellow chromatographic shift with stop solution (Invitrogen), absorbance read at $450 \mathrm{~nm}$ and "Y" axis plotted as OD units. The IgG fraction of rabbit sera was purified on a $5 \mathrm{ml}$ HiTrap $^{\mathrm{TM}}$ rProtein A FF Column (GE Healthcare, Sunnyvale, CA) following company protocol, desalted, filter sterilized $(0.22 \mu \mathrm{m})$, and the protein concentration was determined by BCA. Rabbit anti-SCNH2 serum was selectively absorbed against targeted peptides using a solid phase capture technique. In brief, under sterile conditions, $15 \mathrm{ml}$ conical polystyrene test tubes (BD Falcon) were coated with $8 \mathrm{ml}$ peptide solution (either SCNH2 or APL-36 at 10 $\mu \mathrm{g} / \mathrm{ml}$ in PBS) or $1 \% \mathrm{BSA} / \mathrm{PBS}$, rotated $12 \mathrm{hr}$ at $4^{\circ} \mathrm{C}$, contents removed, blocked with $1 \%$ BSA/PBS, and washed $3 \mathrm{x}$ in $1 \%$ BSA/PBS. In the three prepared tubes, $2 \mathrm{ml} \mathrm{1:100} \mathrm{of} \mathrm{diluted} \mathrm{IgGHIRS} \mathrm{was} \mathrm{added,} \mathrm{rotated} 12 \mathrm{hr}$ at $4{ }^{\circ} \mathrm{C}$, the contents were then removed, and a titration for binding $\mathrm{SCNH} 2$ determined as described above, and resulting samples then used for bioassays and IHC analysis of tissue specimens.

\subsection{Endothelial Cell Tubule Formation Assay}

Freshly prepared HUVEC cells were seeded at a concen- 
tration of 25,000 cells per well of a 96-well culture plate. The wells were first coated with $50 \mu 1$ of Geltrex ${ }^{\mathrm{TM}}$ basement membrane matrix (Invitrogen). The cells were resuspended in medium at a concentration of $5 \times 10^{5}$ cells $/ \mathrm{ml}$. 25,000 cells were added per well. Positive control cells were cultured with medium supplemented with $1.0 \%$ fetal bovine serum (FBS). Negative control cells were cultured with serum-free medium. Cells were incubated at $37^{\circ} \mathrm{C} / 5 \% \mathrm{CO}_{2}$ with. $\mathrm{SCNH} 2$ at the following concentrations: $1.0 \mathrm{pM}, 10 \mathrm{pM}, 100 \mathrm{pM}, 1 \mathrm{nM}, 10 \mathrm{nM}$, $100 \mathrm{nM}, 1 \mathrm{mM}$, and $10 \mathrm{mM}(\mathrm{n}=3)$. After 6 hours of incubation at $37^{\circ} \mathrm{C}$, images of the experiments were taken using an inverted epi-fluorescent microscope (Olympus, IX70) and the tube length was measured using the WimTube software (WIMASIS, Germany).

\subsection{Rat Aortic Ring Assay}

This procedure followed the previously described protocols [20]. In brief, the aorta from 5 wk old male F344 rats was excised cleaned of fat, sectioned into $2 \mathrm{~mm}$ rings, and embedded into the rat tail collagen type I. All the procedures followed the institute ACUC approved guidelines. The aortic rings were incubated at $37^{\circ} \mathrm{C} 5 \%$ $\mathrm{CO}_{2}$ and sprouting vessels were counted 3 - 6 days following the exposure to respective peptides concentrations $(n=4)$.

\subsection{Chorioallantoic Membrane in Chick Embryo (CAM) Assay}

Angiogenesis assays were performed as described previously [21]. Briefly, implants were generated by overlaying two gridded plastic meshes and embedding them into $30 \mu \mathrm{l}$ of $1.6 \mathrm{mg} / \mathrm{ml}$ rat tail collagen (BD Biosciences) and test compounds. The implants were placed on the CAM of 10-day-old shell-less embryos. Implant-bearing embryos were incubated for 66 hours at which time the extent of implant vascularization was quantified. Newly formed vessels were identified by analyzing the upper plane of the implant with a dissecting microscope. Images were captured at $6.3 \mathrm{x}$ using a StereoLumar.V12 fluorescence dissection microscope (Carl Zeiss). The angiogenic index of each implant was determined as the percentage of grids that contained newly formed blood vessels out of the total number of grids in the upper mesh.

\subsection{Western Blot/Phosphorylation Assays of Signaling Pathways}

NMuMG, MCF-7, or HMEC- 1 cells were seeded in 60 $\mathrm{mm}$ plates $\left(6 \times 10^{5}\right.$ to $1.2 \times 10^{6}$ cells/plate $)$ and they were serum starved for 24 hours. The following day, the cells were stimulated with various concentrations of APL-13, $\mathrm{SCNH} 2, \mathrm{SCOH}$, and SCGly peptides over various different times at $37^{\circ} \mathrm{C} / 5 \% \mathrm{CO}_{2}$. Protein extraction and Western blot analysis were performed as previously described [17]. Protein lysates (20 mg/sample) were separated on a $10 \%$ SDS-PAGE gel, transferred to Immobilon $\mathrm{P}$ membranes and blocked in 5\% nonfat milk for $1 \mathrm{hr}$ at room temperature. The blots were incubated with specific anti-phospho MAPK (Thr202/Tyr204) (1:1000) (D.13.14.4E, Cell signaling) or anti-phospho Akt (Ser473) (1:1000) (D9E, Cell Signaling) rabbit monoclonal antibodies overnight at $4^{\circ} \mathrm{C}$. After incubation with a goat anti-rabbit IgG conjugated with horseradish peroxidase (Amersham), the immunoreactive bands were detected by enhanced chemiluminescence (Amersham). To ensure equal loading of proteins, the blots were stripped and re-probed with total MAPK (1:2000) (137F5, Cell Signaling) or total Akt (1:2000) (C67E7, Cell Signaling) rabbit monoclonal antibodies or with $\beta$-actin (1:5000) mouse monoclonal antibody (Sigma). In the experiments with PTX, cells were pretreated over- night with various concentrations of PTX in serum-free medium. They were then incubated for $10 \mathrm{~min}$ at $37^{\circ} \mathrm{C}$ with $100 \mathrm{pM} \mathrm{APL}-13$ or $100 \mathrm{pM} \mathrm{SCNH} 2$.

\subsection{Cell Migration/Invasion Assays}

For both cell migration and invasion assays, 96-well Chemo Tx 101-8 plates (Neuroprobe) were used pursuant to the previously reported protocols [16]. The wells of bottom plate contained different reagents in a suitable FBS free medium according to the experiments. The wells of top membrane plate hold 8000 - 10,000 cells/ well (The uncoated wells are for migration assay while the pre-coated with rat tail collagen type I are for invasion assay) in a suitable FBS free medium and incubated at $37^{\circ} \mathrm{C} / 5 \% \mathrm{CO}_{2} / 100 \%$ humidity for $5-24$ hours. Membrane were removed and fixed in methanol for 5 minutes each. The cells stained in $0.5 \%$ crystal violet, top layer of cells removed, the membrane plate was dried, and the bottom adherent cells were photographed for counting (ImageJ).

\subsection{FACS Sorting Assay}

MB435 cells were dissociated when they reached $70 \%$ $80 \%$ confluency in the culture. The cells were washed $3 x$ in RPMI 1640 medium with 5\%FBS and resuspended in the same medium. Following 1 hour incubation on a shaker for antigen recovery at room temperature, the cells were washed $3 x$ in PBS and suspended in PBS with $1 \%$ BSA at $1 \times 10^{7}$ cells $/ \mathrm{ml} .5 \times 10^{5}$ cells were incubated with 1:100 streptavidin-Alexa 488 (SA 488, Invitrogen) and $5 \mu \mathrm{M}$ of bSCNH2 $+10 \mu \mathrm{g} / \mathrm{ml}$ of SA488 $(1: 100)$ and placed on ice for 15 minutes and centrifuged for 5 minutes at $4^{\circ} \mathrm{C}$. The cells were suspended in $0.5 \mathrm{ml}$ of PBS with $1 \%$ BSA for analyzing and sorting using a 
FACS (ARIA II, BD). Cells with positive signals in the 488-channel (now referred to as enriched MB435 cells) were sorted for further culturing. We used the same procedures to perform a binding inhibition assay to determine the specificity of the SCNH2 receptor recognition in MB435 cells. The enriched MB435 cells were incubated with $50 \mu \mathrm{M}$ of SCNH2, APL-13, other glycine amide peptides LHRH, AVP and OXT, and other C-terminal amides such as AM and GRP following the incubation of $5 \mu \mathrm{M}$ of bSCNH2 $+10 \mu \mathrm{g} / \mathrm{ml}$ of SA488. The positive control was incubated with the incubation of $5 \mu \mathrm{M}$ of $\mathrm{bSCNH} 2+10 \mu \mathrm{g} / \mathrm{ml}$ of SA488 and the negative control was incubated with $10 \mu \mathrm{g} / \mathrm{ml} \mathrm{SA} 488$. All of the experiments were then analyzed using the FACS.

\subsection{Immunohistochemical (IHC) Staining}

Human tumor cell lines/tumor tissue arrays and human placenta tissue were acquired through IRB approved protocols (TARP, LP, CCR NCI). Paraffin sections were deparaffinized in xylene and rehydrated in a graded series of ethanol. To prepare the cytospinning slides of MB435 cells, we suspended 50,000 dissociated cells in 1 $\mathrm{ml}$ of PBS and added a $100 \mu \mathrm{l}$ solution to a Cytoslide loaded onto a Cytofunnel. The cells were centrifuged for 5 minutes at speed $1,000 \mathrm{rpm}$ using a Cytocentrifuge (Thermo Scientific). The slide was washed in PBS before any further IHC analysis. Endogenous peroxidase was blocked using a 3\% hydrogen peroxidase-methanol solution. A staining procedure was performed using a Histostain-Plus Kit (Invitrogen). 1:6000 diluted IgGHIRS and IgGNRS and 1:2000 diluted anti-APJ antibody were used for the IHC staining. SCNH2 or APL-36 was used for absorption at $50 \mu \mathrm{M}$. Slides were mounted using GVA mounting media.

\subsection{Statistical Analysis}

Statistical analysis was carried out using either Microsoft Excel or Prism using a two-tailed Student's t test. P values less than 0.05 were considered statistically significant.

\section{RESULTS}

\subsection{Identification of SCNH2 as a Mitogen in Endothelial, NMuMG, Tumor and Mast Cells}

Peptide amidation is one of the most important biosynthetic events in the production of bioactive peptide hormones $[9,11]$. The conserved amidation motif indicates multiple bioactivities $[9,10,22]$. Our C-terminal glycine amide SCNH2 was shown to be highly conserved in mammalian/marsupial species but is not expressed in lower vertebrates (Figure 1(a)). Therefore, the conserved evolutionary amidation motif we have identified suggests that $\mathrm{SCNH} 2$ may function as a pluripotent peptide. Accordingly, of the three peptide derivatives evaluated (SCNH2, SCOH and SCGly), only the peptide amide proved to be mitogenic (Figure 1(b)).

Cell proliferation is a key process driving angiogenesis, carcinogenesis and embryogenesis [23]. Compared to the controls, we demonstrate that nanomolar (nM) concentrations of SCHN2 can significantly ( $p<0.001-0.05$, Figure 1(b)) stimulate the growth of a variety of anatomically distinct cell populations that include endothelial (HUVEC, HMEC-1, and PAE), epithelial (NMuMG), tumor (MCF-7, HTB-103, T47D, HT-1080, and SK-LMS-1) mast cells (HMC-1) and however, neither SCOH nor SCGly showed any stimulated effects on endothelial (HMEC-1) and tumor cells (MB435) $(p>0.05$, Figure 1(b)). Hence, our cell growth data strongly confirmed that C-terminal amidation plays a critical role in the trophic activity of SCNH2 [10,11].

\subsection{Rabbit Anti-SCNH2 Hyperimmune Serum Specificity and Purification}

To identify the binding specificity of purified hyperimmune rabbit anti-SCNH2 IgG (IgGNRS) should be "IgGHIRS" for SCNH2, we performed modified ELISA (Figure 2). IgGHIRS selectively bound to $\mathrm{SCNH} 2$ with some cross-reaction to its precursor APL-36 but had minimal binding activities to any other peptides (Figure 2). As expected, IgGNRS did not bind to any peptides (Figure 2(b)). IgGHIRS exclusively bound to $\mathrm{SCNH} 2$ following exposure of APL-36 (Figure 2(c)), while the binding activity of IgGHIRS dramatically diminished following absorption with SCNH2 (Figure 2(d)).

\subsection{SCNH2, IgGHIRS, and in Vitro/in Vivo Angiogenesis}

Angiogenesis is the primary pathological process for the development of nearly all solid tumor growth and a critical step for tumor metastasis $[24,25]$. Moreover, because APL-13 promotes angiogenesis [6-8], we assessed whether SCNH2 had a similar function. First, we evaluated the effects of SCNH2 on HUVEC cell tubule formation. During a 6-hour exposure, compared to the control, we observed a classic rise/fall response with $\mathrm{SCNH} 2$ inducing maximal tube formation at $10 \mathrm{nM}(\mathrm{p}<0.05$, Figure 3(a)), while the $\mathrm{SCOH} / \mathrm{SCGly}$ derivatives proved non-functional $(\mathrm{p}>0.05$, Figure 3(a)). The representative images of tube formation for the control and SCNH2 at $10 \mathrm{nM}$ are shown here (Figure 3(a)). Then, we assessed a dose-response of SCNH2 in the rat aortic ring assay. $\mathrm{SCNH} 2$ at $100 \mathrm{pM}$ induced early vessel sprouting at 3 days resulting in a 2-fold increase in microvessel formation over the control $(p<0.01$, Figure 3(b)), while 
APL-13 at $10 \mathrm{nM}$ induced maximal vessel sprouting but

took 6 days $(\mathrm{p}<0.05$, Figure 3(b)). However, not all of

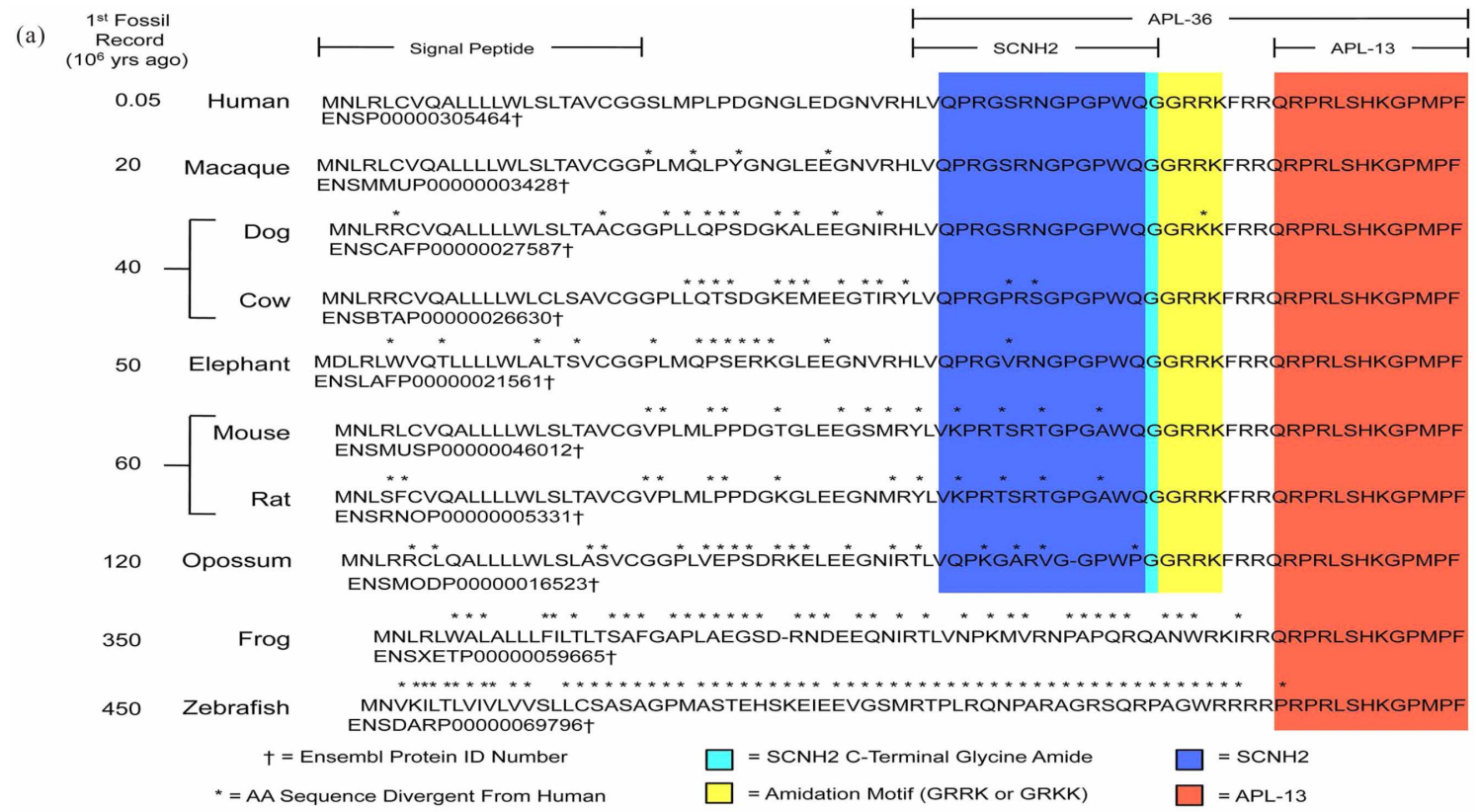

(b)
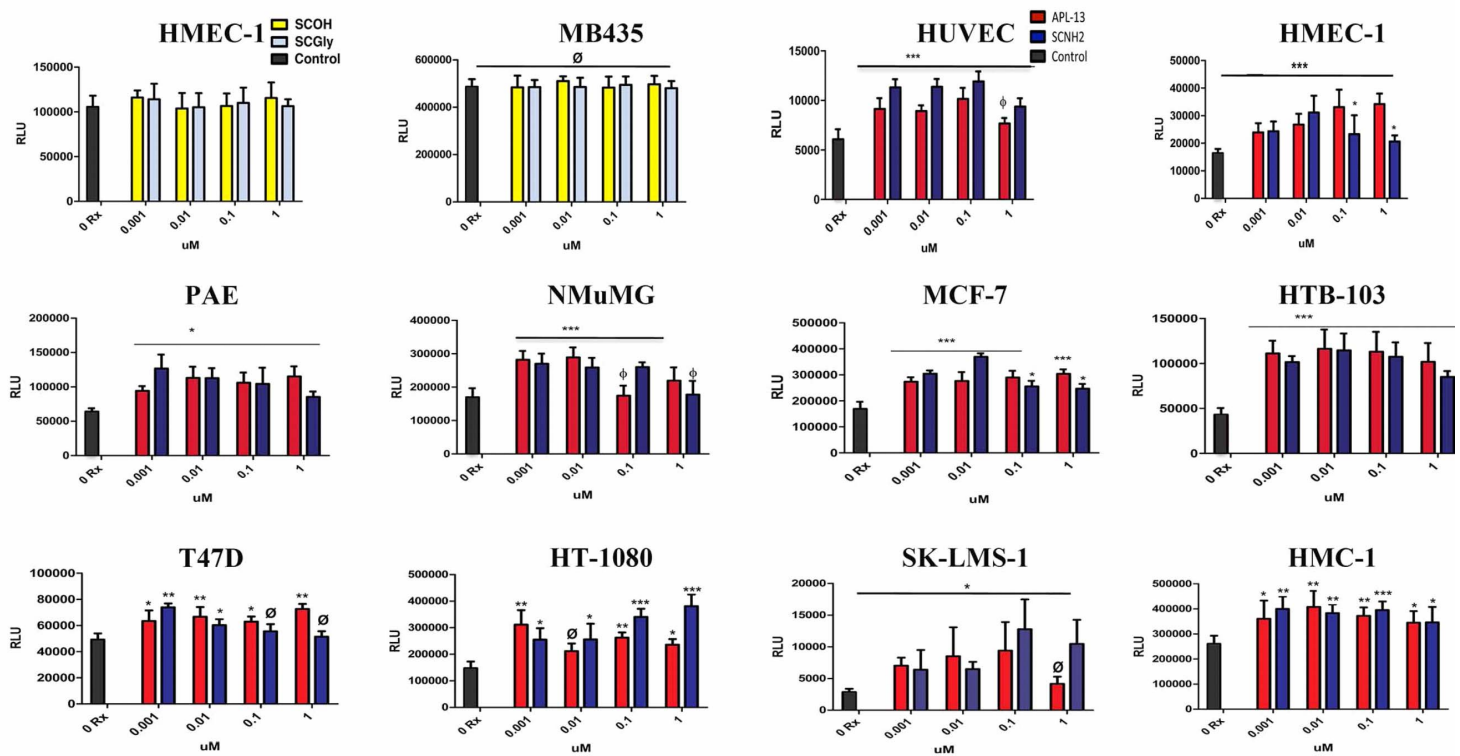

Figure 1. Identification of a novel apelineric member, SCNH2, and its mitogenic bioactivities. (a) An evolutionary comparison of the APL pre-prohormone expressed in mammals, amphibians and fish (covering 450 million year of genetic adaption). The conservation of the amino acid sequence for APL-13 is indicated in red, encoded amidation motif identified in yellow, amino acid amide in cyan, and remaining SCNH2 sequence highlighted in blue. Cell proliferation (ATPLite) assays [plotted as "relative luminescent units" $(R L U)$ ]. (b) Evaluation of cell growth induction of $\mathrm{SCNH} 2$, SCOH, and SCGly on endothelial and tumor cells. Abbreviations: SCNH2, salcut-NH2; SCOH, peptide with free acid; SCGly, peptide with a glycine-extended intermediate; SCNH2, salcut-NH2; APL-13, apelin-13; MB435, human breast carcinoma cell line; HUVEC, primary human umbilical endothelial cell line; HMEC-1, immortalized human microvascular endothelial cell line; HTB-103, human gastric carcinoma cell line; T47D, human breast cancer cell line; MCF-7, human breast adenocarcinoma cell line; HT-10180, human fibrosarcoma cell line; PAE, immortalized porcine aortic endothelial cell line; NMuMG, immortalized normal murine mammary gland epithelial cell line; SK-LMS-1, human leiomyosarcoma cell line; and HMC-1, immortalized human mast cell line. All values are mean \pm $\mathrm{SD}(\mathrm{n}=8),{ }^{*} \mathrm{p}<0.05,{ }^{* *} \mathrm{p}<0.01 ;{ }^{* * *} \mathrm{p}<0.005, \varnothing=$ not significant. 
(a) IgGHIRS

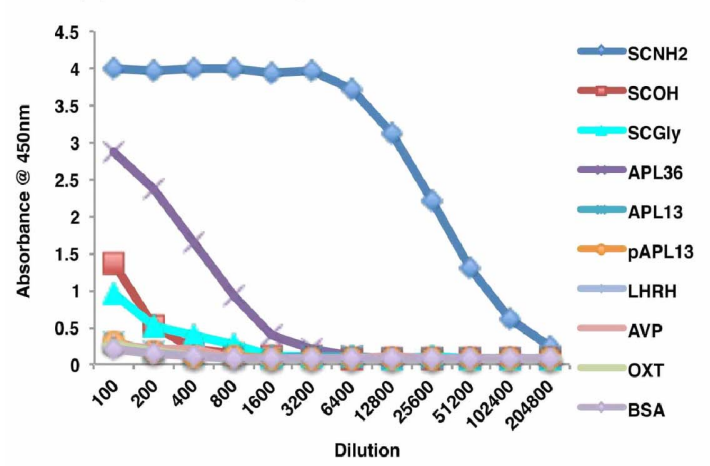

(c) IgGHIRS/APL-36 Absorbed

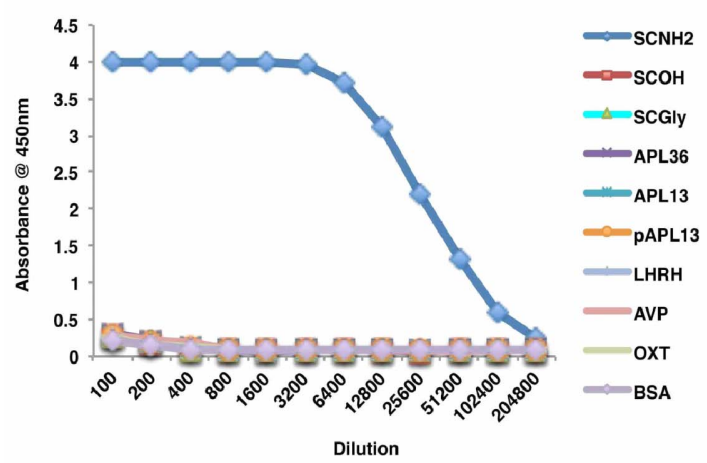

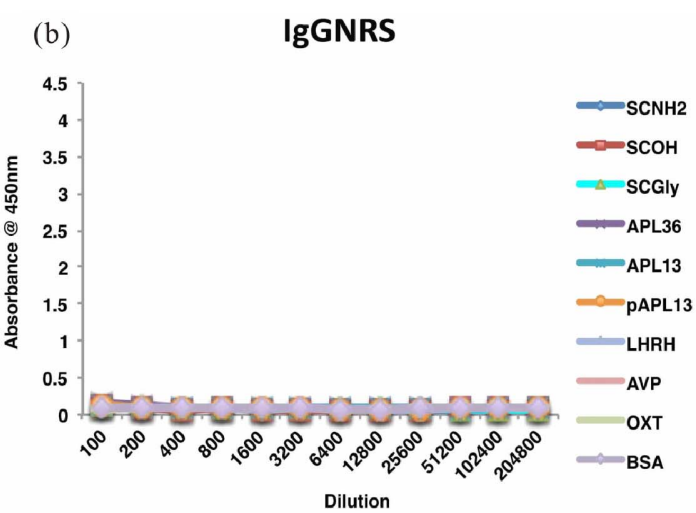

(d) IgGHIRS/SCNH2 Absorbed

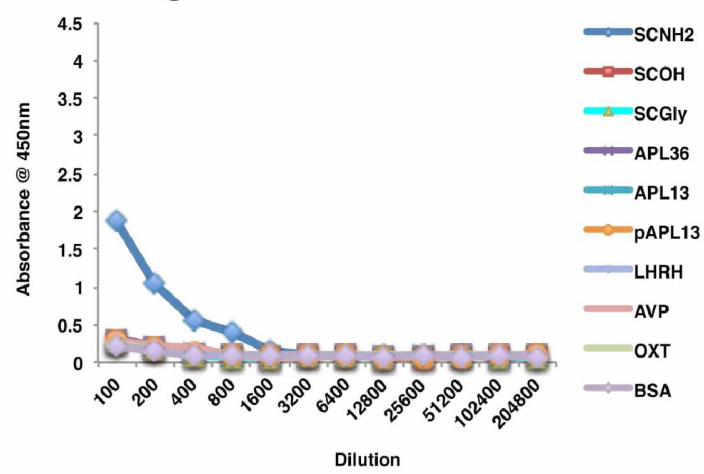

Figure 2. Characterization of IgGHIRS on solid phase peptide targets using ELISA assays. Binding specificities of IgGHIRS and IgGNRS to SCNH2, APL-13, APL-36, other glycine amide peptides of LHRH, AVP and OXT. (a) IgGHIRS binding showing mild cross-reactivity with APL-36 and slight interaction with SCOH and SCGly; (b) IgGNRS is ineffective in interacting with any solid phase tested peptides. Effect APL-36 or SCNH2 absorption on antibody activity. (c) APL-36 absorption removed cross-reacting components present in IgGHIRS. (d) SCNH2 absorption dramatically reduced the binding capabilities of IgGHIRS to SCNH2. Abbreviations: IgGHIRS, purified rabbit anti-SCNH2 hyperimmune IgG; IgGNRS, normal rabbit IgG; SCNH2, salcut-NH2; APL-13, apelin-13; APL-36, apelin-36; LHRH, luteinizing hormone-releasing hormone; AVP, arginine vasopressin; OXT, oxytocin; GRP, gastrin-releasing peptide; $\mathrm{SCOH}$, peptide with free acid; and SCGly, peptide with glycine-extentded intermediate. $\mathrm{n}=8$.

the angiogenic compounds tested in vitro necessarily have angiogenic effects in vivo. Therefore, we investigated the in vivo angiogenic activity of $\mathrm{SCNH} 2$ and APL-13 using the CAM assay. SCNH2 and APL-13 dramatically induced neovascularization at all of the tested concentrations ( $p<0.005$, left in Figure 3(c)). $\mathrm{SCNH} 2$ at $1 \mathrm{nM}$ and APl-13 at $100 \mathrm{nM}$ induced the maximum neovascularization $(p<0.005$, left in Figure 3(c)) but there was no statistical difference between these two groups and VEGF-A at $1 \mathrm{nM}(\mathrm{p}>0.05$, left in Figure 3(c)) Interestingly, IgGHIRS dramatically suppressed SCNH2 vessel formation (91.3\% inhibition) and partially blocked APL-13 activity (51.2\% inhibition) ( $p<0.005$, middle in Figure 3(c)), while IgGNRS was ineffective. SCNH2 was significantly more potent than APL-13 in inducing in vivo angiogenesis $(\mathrm{p}<0.005$, left and middle in Figure 3(c)). In addition, $\mathrm{SCNH} 2$ is more potent than VEGF-A in modulating a CAM response at $1 \mathrm{pM}(\mathrm{p}<$ 0.005, right in Figure 3(c)). Considering that SCNH2 is an angiogenic agent in vitro and in vivo and far more potent than APL-13 and VEGFA, SCNH2 may play a more critical role in vessel formation than any other known angiogenic growth factor.

\subsection{SCNH2 Induced Phosphorylation of p44/42 MAPK and PI3K/Akt Signaling Pathways in NMuMG, MCF-7, and HMEC-1 Cells}

APL-13 modulates the PI3K/Akt and p44/42 MAPK signaling pathways in NMuMG [26,27]. For purposes of comparison, we assessed whether and how SCNH2 induces p44/42 MAPK and PI3K/Akt phosphorylation (P-p44/42 MAPK and P-PI3K/Akt) using the NMuMG cells and found differences in the potency of peptide-induced signaling (Figure 4(a)). Compared to the control, SCNH2 augmented 28, 22, 22, and 17 folds of P-PI3K/Akt at $100 \mathrm{pM}, 1 \mathrm{nM}, 100 \mathrm{nM}$, and $1 \mu \mathrm{M}$, respectively, while it induced 8, 5, 4, and 2 folds of P-p44/42 MAPK at 100 pM, $1 \mathrm{nM}, 100 \mathrm{nM}$, and $1 \mu \mathrm{M}$, 
respectively (Figure 4(a)). However, APL-13 only induced a maximum of 8 and 5 folds of P-PI3K/Akt and P-p44/42 MAPK compared to the control, respectively (Figure 4(a)). SCNH2 even increased phosphorylation of these pathways at $0.1 \mathrm{pM}$ (data not shown). In addition, we evaluated the SCNH2-induced phosphorylation of these two signaling pathways over a time course in NMuMG cells from 5 minutes to 1 hour (Figure 4(b)). SCNH2 regulates the P-PI3K/Akt and P-p44/42 MAPK signaling pathways differently. SCNH2 has a transient effect on p44/42 MAPK (15 folds) activation for only 5 minutes but maintains long-term P-PI3K/Akt (10 folds) (Figure 4(b)) up to 1 hour at $1 \mathrm{nM}$. This suggests that $\mathrm{SCNH} 2$ may play distinct roles through these signaling pathways from that of APL-13.

Previous studies showed that the SM inhibitors to p44/42 MAPK (U0126) and PI3K/Akt (LY294002) block

(a)
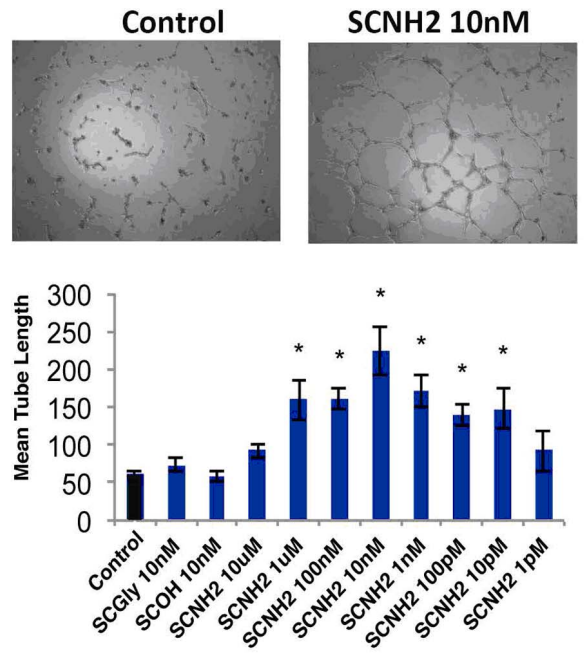

the phosphorylation of these signaling pathways $[17,18]$. We therefore evaluated whether these SM inhibitors are able to block the phosphorylation activities induced by SCNH2 in the MCF-7 (Figure 4(c)) and HMEC-1 cells (Figure 4(d)). As expected, these SM inhibitors blocked the SCNH2-induced phosphorylation of these pathways. U0126 suppressed 97\% of SCNH2 and APL-13 induced phosphorylation of the p44/42 MAPK signaling pathway, while LY294002 blocked $75 \%$ of APL-13 and $93 \%$ of $\mathrm{SCNH} 2$ of the peptide-induced phosphorylation of PI3K/Akt (Figure 4(c)). U0126 suppressed 95\% of APL-13 and $98 \%$ of SCNH2 of p44/42 MAPK and LY294002 inhibited $98 \%$ of APL-13 and $96 \%$ of SCNH2 of $\mathrm{PI} 3 \mathrm{~K} / \mathrm{Akt}$ of the peptide-induced phosphorylation (Figure 4(d)). These results demonstrate that SCNH2 is bioactive through these signal-regulated kinases in NMuMG, endothelial, and tumor cells.

(c)
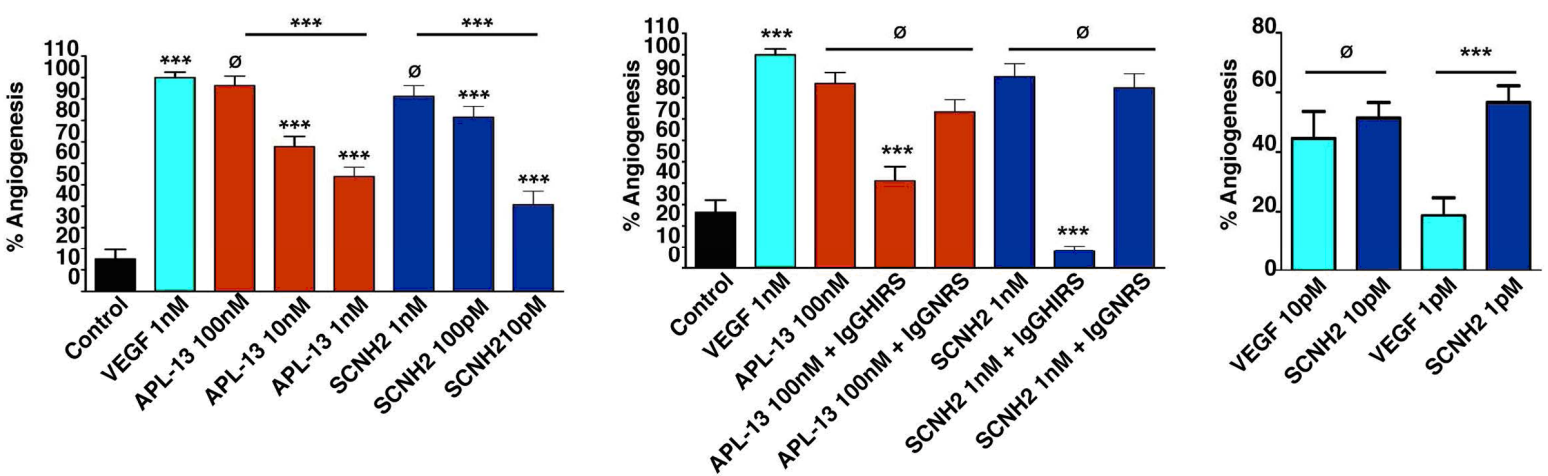

Figure 3. SCNH2 and APL-13 induced in vitro/in vivo angiogenesis. (a) Tubule formation on HUVECs). Top: images results of the negative control and SCNH2 at $10 \mathrm{nM}$ and bottom: a dose-response of SCNH2. All values are mean \pm SD $(\mathrm{n}=3),{ }^{*} \mathrm{p}<$ 0.05. (b) Rat aortic ring vessel sprouting for in vitro angiogenesis. SCNH2 mediated vessel formation at 3 days and APL-13 mediated vessel formation at 6 days. All values are mean $\pm \mathrm{SD}(\mathrm{n}=6) ;{ }^{*} \mathrm{p}<0.05{ }^{* *} \mathrm{p}<0.01$. (c) CAM assays for in vivo neovascularization. Left: comparison of VEGF-A, APL-13, and SCNH2 induced neovascularization; middle: Effect of IgGHIRS versus IgGNRS $(100 \mu \mathrm{g} / \mathrm{ml})$ on APL-13 or SCNH2 induced vessel formation; and right: comparison of VEGFA and SCNH2 induced neovascularization. Abbreviations: SCNH2, salcut-NH2; APL-13, apelin-13; VEGFA, vascular endothelial growth factor A; CAM, chorioallantoic membrane; and HUVEC, primary human umbilical vascular endothelial cell line. All values are mean $\pm \operatorname{SD}(\mathrm{n}<30),{ }^{* * *} \mathrm{p}<0.005, \varnothing=$ not significant. 
(a)

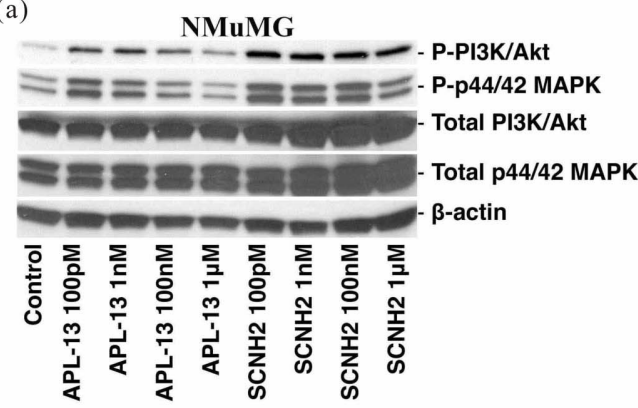

(c)

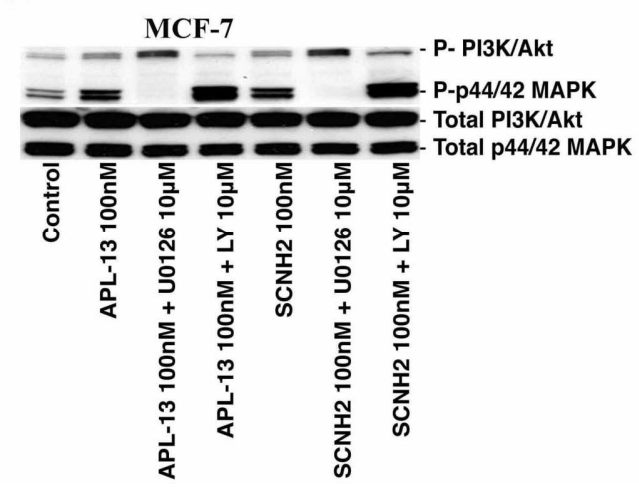

(b)

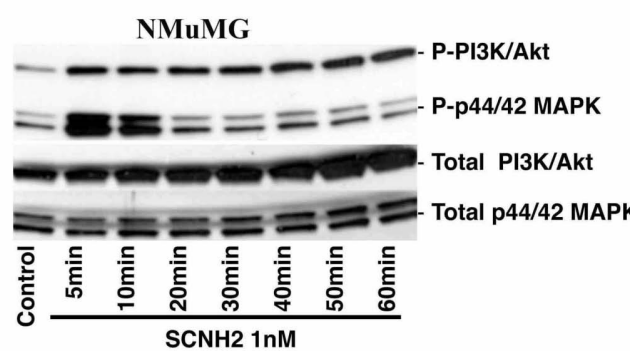

(d)

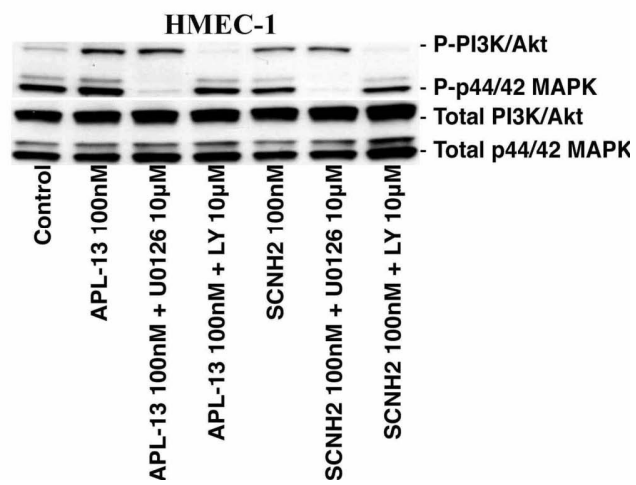

Figure 4. SCNH2-activated phosphorylation of PI3K/Akt and p44/42 MAPK signaling pathways using Western-Blotting assays. P-p44/42 MAPK P-PI3K/Akt on NMuMG. (a) Peptide induced dose responses. (b) Time course study of SCNH2. Peptide activated signaling pathways and the effect of SM inhibitors, U0126 ( $p 44 / 42$ MAPK inhibitor) and LY294002 (PI3K/Akt inhibitor), on the induced phosphorylation. (c) MCF-7 and (d) HMEC-1. Abbreviations: SCNH2, salcut-NH2; APL-13, apelin-13; and SM, small molecule; NMuMG, immortalized murine mammary gland epithelial cell line; and HMEC-1, immortalized human microvascular endothelial cell line.

\subsection{SCNH2 and Migration/Invasion of Endothelial, NMuMG, and Tumor Cells}

Cell proliferation, migration, and invasion are critical events of embryogenesis, wound healing, and malignant diseases [24,25]. However, these events may not share the same signaling pathways. Therefore, in addition to evaluating $\mathrm{SCNH} 2$ on cell proliferation, we examined the effects of SCNH2 and APL-13 on human endothelial/tumor cell migration/invasion, as well as the characteristics and suppressive activities of IgGHIRS and SM inhibitors on these activities (Figure 5). Initially, we tested the dose-response of SCNH2, APL-13, and VEGFA to the cell migration of HUVEC cells to identify the maximum induction concentration. The peptide response hierarchy was SCNH2 > VEGF-A > APL-13 in molar potency for mediating cell movement (Figure 5(a)). This indicates that $\mathrm{SCNH} 2$ is more potent that VEGF-A and APL-13 regarding cell migration. Using maximal stimulating concentrations for SCNH2 (10 pM) and APL-13 (10 nM), we assessed IgGHIRS and SM compounds for their ability to block peptide-induced bioactivities (Figures 5(b)-(l)). IgGHIRS, but not IgGNRS, significantly suppressed SCNH2 and partially blocked APL-13 activity in endothelial and tumor cells (Figures 5(b)-(l)), reflecting what we observed in our CAM analysis (middle in Figure 3(c)). The SM inhibitors of U0126 (p44/42 MAPK), LY294002 (PI3K/Akt), LY2228820 (p38 MAPK), and AMD3100 (CXCR4) [17,18] all effectively suppressed SCNH2 and APL-13 induced cell migration and invasion (Figures $\mathbf{5 ( b )}$-(l)). The data suggests that $\mathrm{SCNH} 2$ mediates its functions via PI3K/Akt, p38 and p44/42 MAPKs, and CXCR4 pathways.

\subsection{Characterization of the Putative SCNH2 Receptor in MB435 Cells}

To characterize the putative $\mathrm{SCNH} 2$ receptor, we employed a FACS assay with (bSCNH2) and (SA488) to target responding MB435. Initially, we tested whether bSCNH2 is actively similar to $\mathrm{SCNH} 2$. The results showed that both peptides are mitogenic (Figure 6(a)). We then per- formed the FACS assay using bSCNH2 to sort the SCNH2 receptor positive cells, which we termed en- riched MB435. The non-specific signal noise was approximately $0.6 \%$ in the negative control (Parent, Figure 


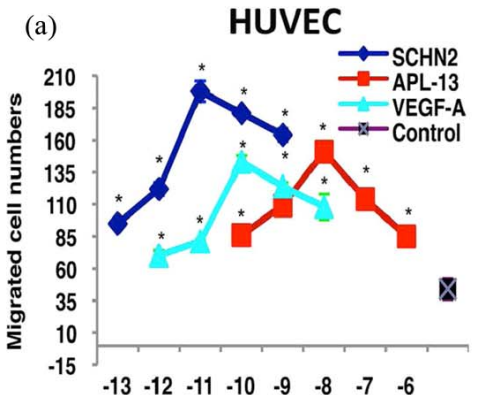

LOG10 [Peptide M]

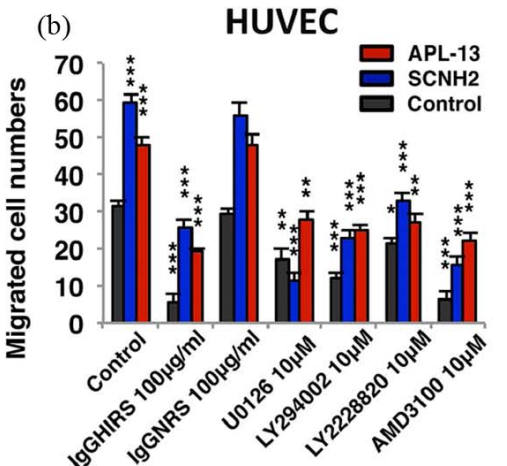

MCF-7

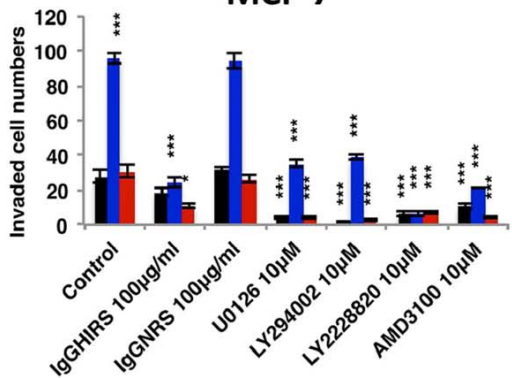

MB435

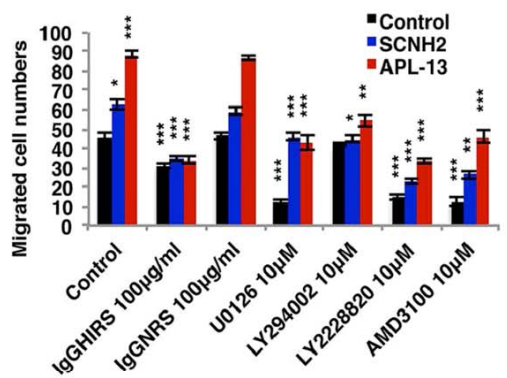

LEC-1

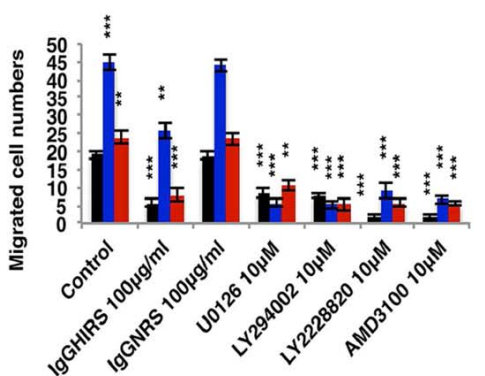

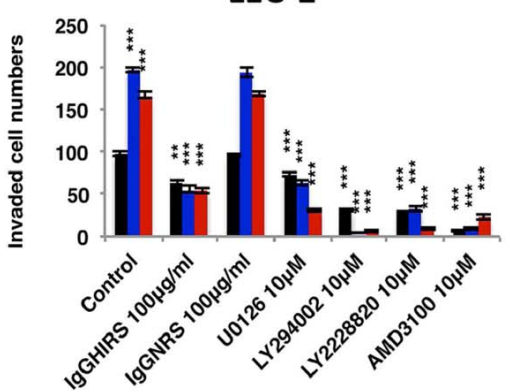

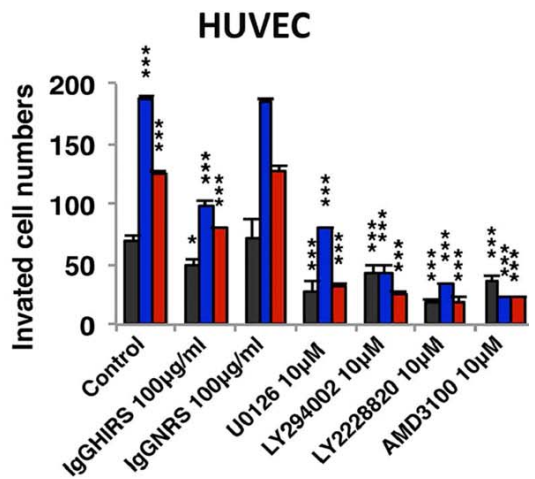

92.1

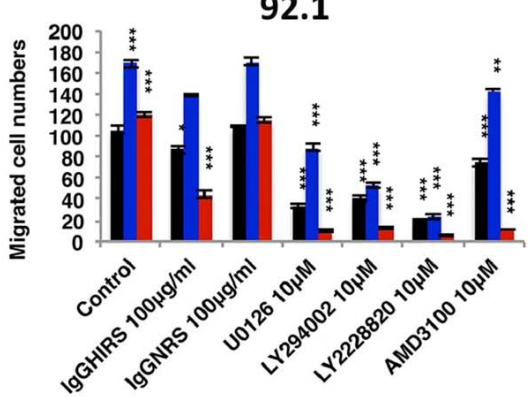

MB435

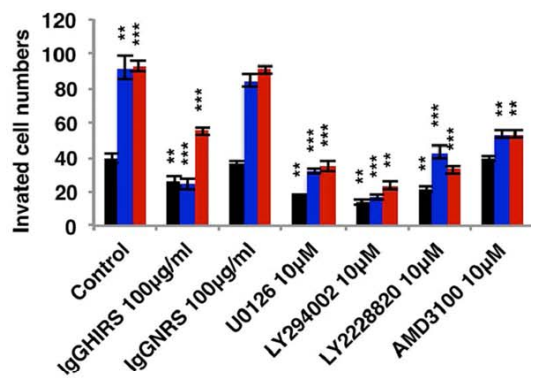

SK-LMS-1

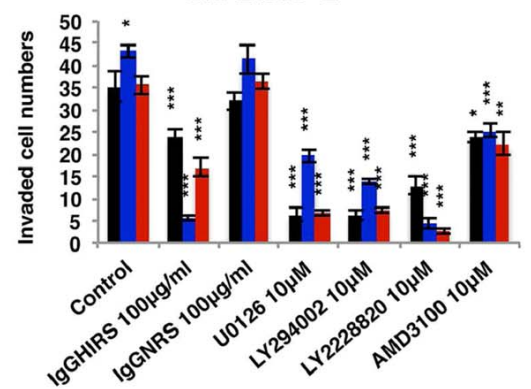

Figure 5. SCNH2 induced cell migration/invasion with and without IgGHIRS, IgGNRS, and SM inhibitors on endothelial and tumor cells. (a) Comparison of SCNH2, VEGF-A, and APL-13 induced HUVEC cell migration. Migration/invasion (through type I rat-tail collagen) mediated by SCNH2 $(10 \mathrm{pM})$ and APL-13 $(10 \mathrm{nM})$ compared to negative control and the effects of immune reagent (IgGHIRS or IgGNRS, $100 \mu \mathrm{g} / \mathrm{ml})$ or the selected SM inhibitors $(10 \mu \mathrm{M})$ on the induced migration/invasion. The p44/42 MAPK inhibitor (UO126), the PI3K/Akt inhibitor (LY294002), the p38 MAPK inhibitor (LY2228820) and the CXCR4 inhibitor (AMD3100) were used. (b) The results of migration and invasion on different endothelial and tumor cell lines. Abbreviations: SCNH2, salcut-NH2; APL-13, apelin-13; VEGFA, vascular endothelial growth factor A; IgGHIRS, purified rabbit anti-SCNH2 hyperimmune IgG; Normal rabbit IgG, IgGNRS; SM, small molecule; HUVEC, primary human umbilical vascular endothelial cell line; MCF-7, human breast adenocarcinoma; 92.1, human ocular melanoma; MB435, human breast carcinoma; LEC-1, immortalized human lymphatic endothelial cell line; SK-LMS-1, human leomyosarcoma; SCOH, peptide with free acid; and SCGly, peptide with glycine-extentded intermediate. All values are mean $\pm \mathrm{SD}(\mathrm{n}=3),{ }^{*} \mathrm{p}<0.05,{ }^{* * *} \mathrm{p}<0.01,{ }^{* * *} \mathrm{p}$ $<0.005$. 
6(b)). $4.8 \%$ of the $\mathrm{SCNH} 2$ receptor positive cells were identified in the positive control (Parent, Figure 6(b)). The enriched MB435 cells were expanded and used in a binding inhibition assay to determine the specificity of the SCNH2 receptor recognition (Enriched, Figure 6(b)). We demonstrated that only SCNH2 blocked the binding of bSCNH2 down to $64 \%$ (Figure 6(b)) while APL-13 (Figure 6(b)), other glycine amide peptides LHRH (Figure 6(b)), AVP (Figure 6(b)) and OXT (Figure 6(b)), and other C-terminal amides such as AM (Figure 6(b)) and GRP (Figure 6(b)) were ineffective (Figure 6(b)). In addition, we showed that the proliferation profile of enriched MB435 cells was shifted to the left on the y-axis demonstrating an enhancement in growth sensitivity to $\mathrm{SCNH} 2$ over that of the parent MB435 cells (Figure 6(c)).

Furthermore, we compared the IHC staining of SCNH2 and the APJ receptor using the MB435 cells (Figure 6(d)). SCNH2 expression was dramatically increased in the enriched MB435 compared to the parent MB435 cells (Figure 6(d)). However, the APJ receptor staining was significantly diminished in the enriched MB435 cells compared to the parent MB435 cells (Figure 6(d)). Hence, these IHC results suggest that $\mathrm{SCNH} 2$ functions through a distinctly different receptor from APJ. Prior reported data has shown that APL-13 triggers kinaseregulated signaling through the PTX-sensitive APJ receptor [19]. We hypothesized that $\mathrm{SCNH} 2$ does not function through the APJ receptor but activates the same signaling pathways differently than APL-13 through an unknown GPCR. Given this possibility, we evaluated the effects of PTX and CTX on SCNH2 induced kinase activation since these toxins have been used to target different $G$ proteins [28-30]. The results showed that SCNH2 signaling was resistant to PTX but sensitive to CTX while APL-13 activities are sensitive to PTX, consistent with the prior data [19], but indifferent to CTX treatment (Figure 6(e)),. The data suggested that $\mathrm{SCNH} 2$ mediates its bioactivities via a non-APJ GPCR.

\subsection{EndoEndogenous SCNH2 in Mouse Embryonic E17 Tissues and Human Placenta, Lung, and Solid Tumor Tissue Arrays}

Finally, to assess the anatomical expression of $\mathrm{SCNH}$, we used IgGHIRS IHC analysis of paraffin embedded tissue from a variety of sources (Figure 7). Human trophoblasts are known to be highly invasive, induce angiogenesis, produce a variety of growth factors, and contain the enzyme repertoire for peptide amidation [31-33]. Accordingly, we performed IHC assays to detect endogenous $\mathrm{SCNH} 2$ in human placenta tissue. Villous cytoplasm of trophoblasts from human placental tissue showed intense staining with IgGHIRS/APL-36 (arrowheads, Figure 7(a), APL-36 absorbed) and clearly diminished staining on exposure to IgGHIRS/SCNH2 (arrowheads, Figure 7(a) $\mathrm{SCNH} 2$ absorbed). IgGNRS was negative for all IHC analysis (Data not shown). Developing organs during embryogenesis have been demonstrated to produce peptide amides that drive growth in an autocrine/paracrine fashion and contain amidation enzymes [34,35]. In E17 tissue, there is an intense SCNH2 staining in the following organs: adrenal and kidney; spinal cord and vertebrate; heart; salivary gland; pancreas; thymus; and lung (Figure 7(a)). Accordingly, augmented endogenous $\mathrm{SCNH} 2$ indicates that the peptide may play a critical role in cell differentiation and embryogenesis.

An analysis of ninety-four patients with non-small cell lung cancer showed that the APL mRNA expression was significantly elevated in tumor tissue compared to normal lung tissue and that messenger levels track with increased microvessel density and poorer prognosis [36]. Based on these clinical correlations, we evaluated $\mathrm{SCNH} 2$ expression on a human tumor tissue. Endogenous SCNH2 was detected with IgGHIRS/APL-36 (APL-36 absorbed in Figure 7(b)), but it dramatically diminished with IgGHIRS/SCNH2 in normal human lung tissue ( $\mathrm{SCNH} 2$ absorbed in Figure 7(b)). Compared to normal tissue (Normal lung in Figure 7(b)), there is dramatic increase of SCNH2 in the following tumor tissues: lung cancer; colon cancer; breast cancer; and ovarian cancer (Figure 7(b)). Overall, the pathological analysis of IHC data in the tumor tissue arrays gave the following breakout scores: breast 37/41 (90.2\%); colon $28 / 29$ (96.6\%); lung 28/32 (87.5\%); and ovary $28 / 37$ (75.6\%). This pilot study demonstrates a trend in enhanced SCNH2 expression for human malignant tumors implicating $\mathrm{SCNH} 2$ as a possible diagnostic biomarker for these malignancies.

\section{DISCUSSION}

The apelinergic system (APL/APJ) is the new therapeutic focus for several human diseases involving inflammation and aberrant cell growth [2]. The apelin gene produces more than one peptide through enzymatic processes and these peptides generally have similar bioactivities in different tissues [2]. Aside from trypsin-like cleavage and aminopeptidase/carboxypeptidase activity in the processing of bioactive peptides from their respective precursor proteins, alternative enzymatic events can play a critical role as well. We identified a classic peptide amidation motif (GRRK or GRKK) [11] in APL-36 and predicted the formation of the bioactive peptide amide $\mathrm{SCNH} 2$ from this precursor concomitantly with APL-13. Given that other peptide amides are proven mitogenic 
(a)
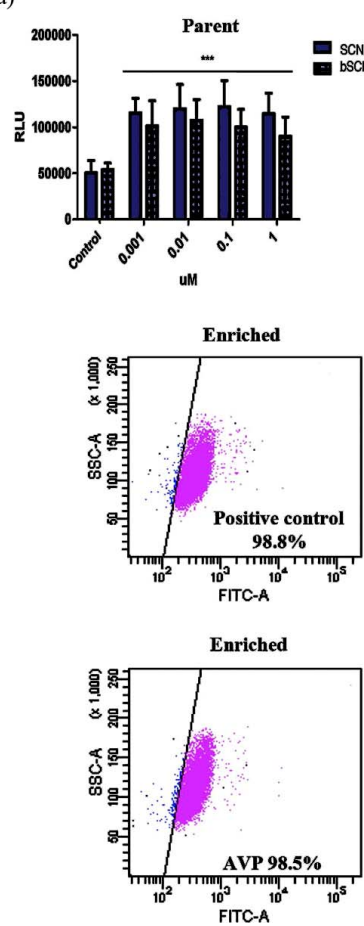

(c)

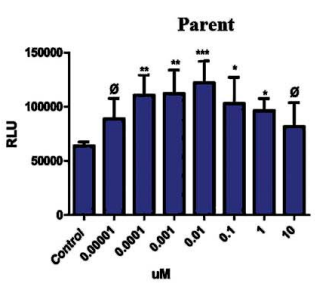

(b)
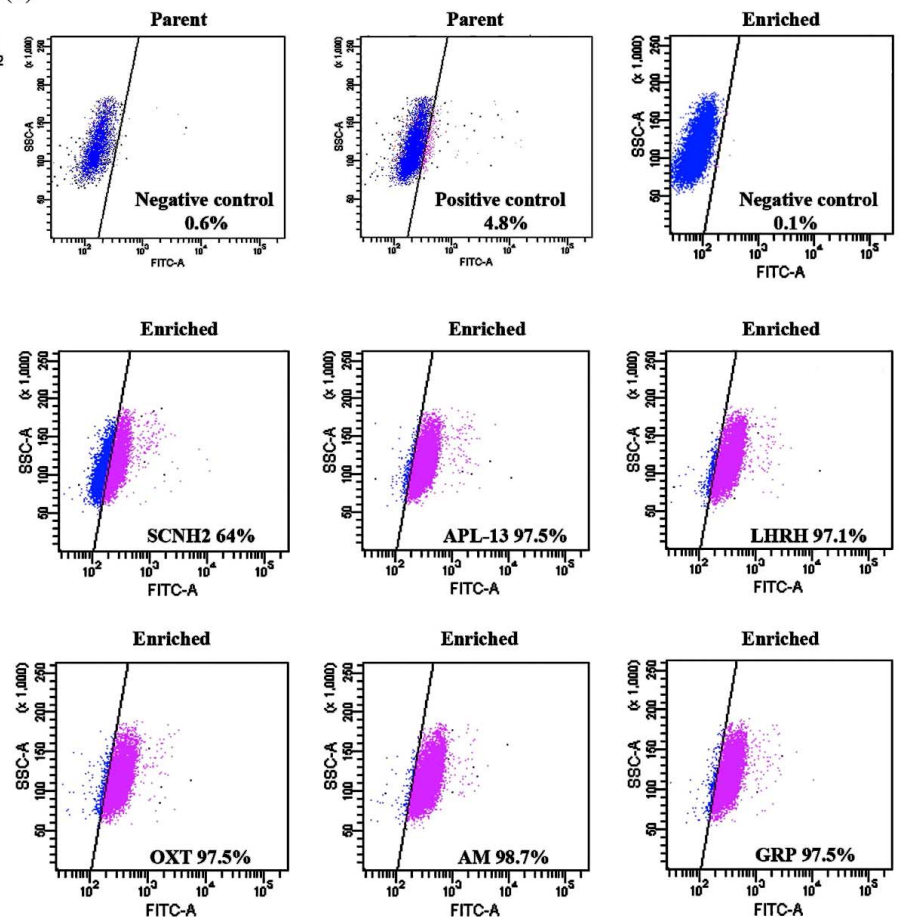

(d) Anti-SCNH2 Anti-APJ receptor

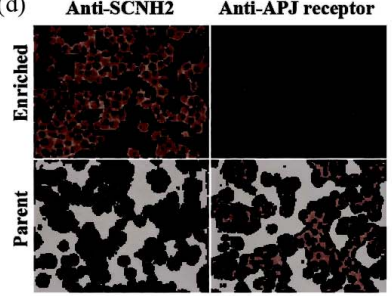

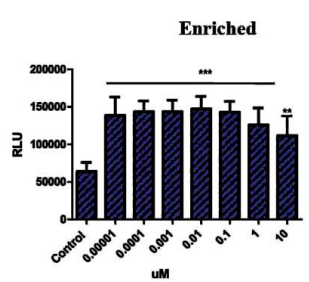

(e)

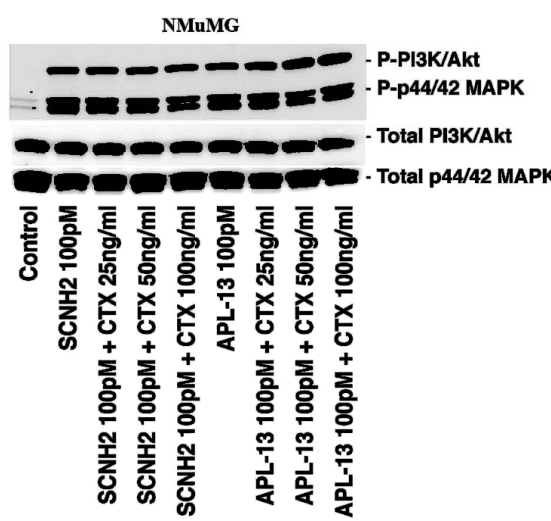

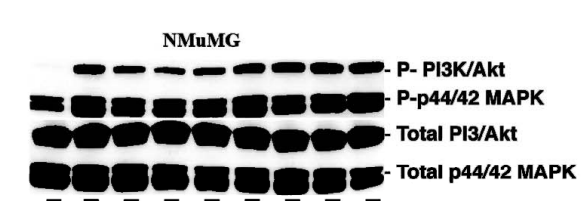

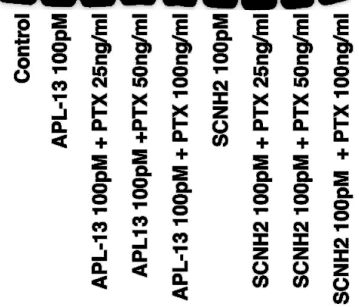

Figure 6. Characterization of $\mathrm{SCNH} 2$ putative receptor using MB435s and NMuMGs. (a) Mitogenic effect comparison between SCNH2 and bSCNH2 on parent MB435s. (b) FACS based receptor binding assay using $5 \mu \mathrm{M}$ of bSCNH2 and $10 \mu \mathrm{g} / \mathrm{ml} \mathrm{SA} 488 \mathrm{with} /$ without pre-incubation of peptide on parent and enriched MB435. (c) Comparison of SCNH2 induced cell growth on parent and enriched MB435 cells. (d) Comparison of IHC staining of SCNH2 and the APJ receptor on parent and enriched MB435 cells. (e) Western-Blotting results of the effects of CTX and PTX on peptide activated PI3K/Akt and p44/42 MAPK signaling pathways. Abbreviations: $\mathrm{SCNH} 2$, salcut-NH2; bSCNH2, biotinylated Salcut-NH2; APL-13, apelin-13; SA488, streptavidin conjugated-Alexa 488; MB435, human breast carcinoma cell line; NMuMG, immortalized murine mammary gland epithelial cell line; LHRH, luteinizing hormone-releasing hormone; AVP, arginine vasopressin; OXT, oxytocin; AM, adrenomedullin; GRP, gastrin-releasing peptide; CTX, choleral toxin; PTX, pertussis toxin; IHC, immunohistochemistry. 
(a)
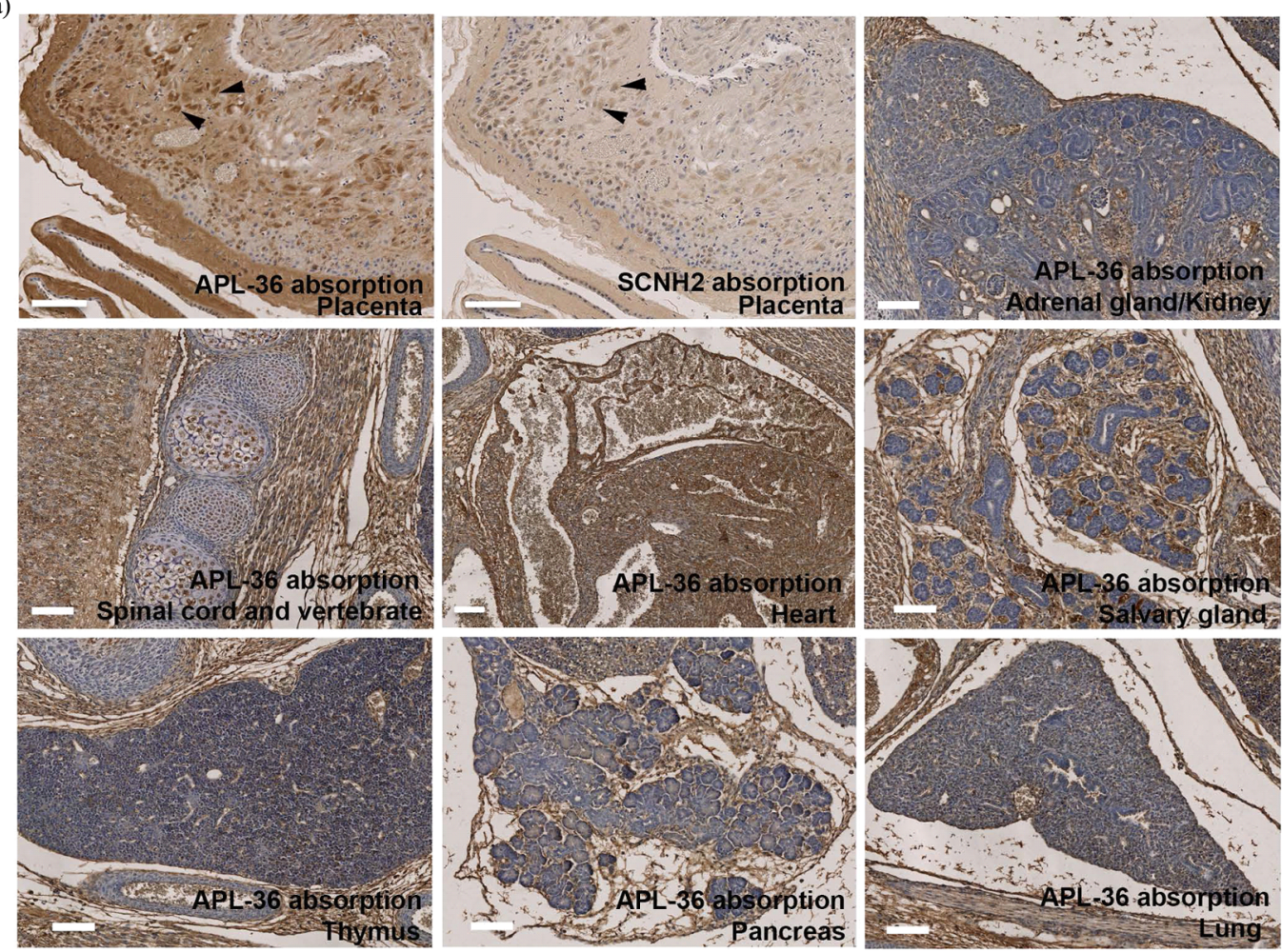

(b)
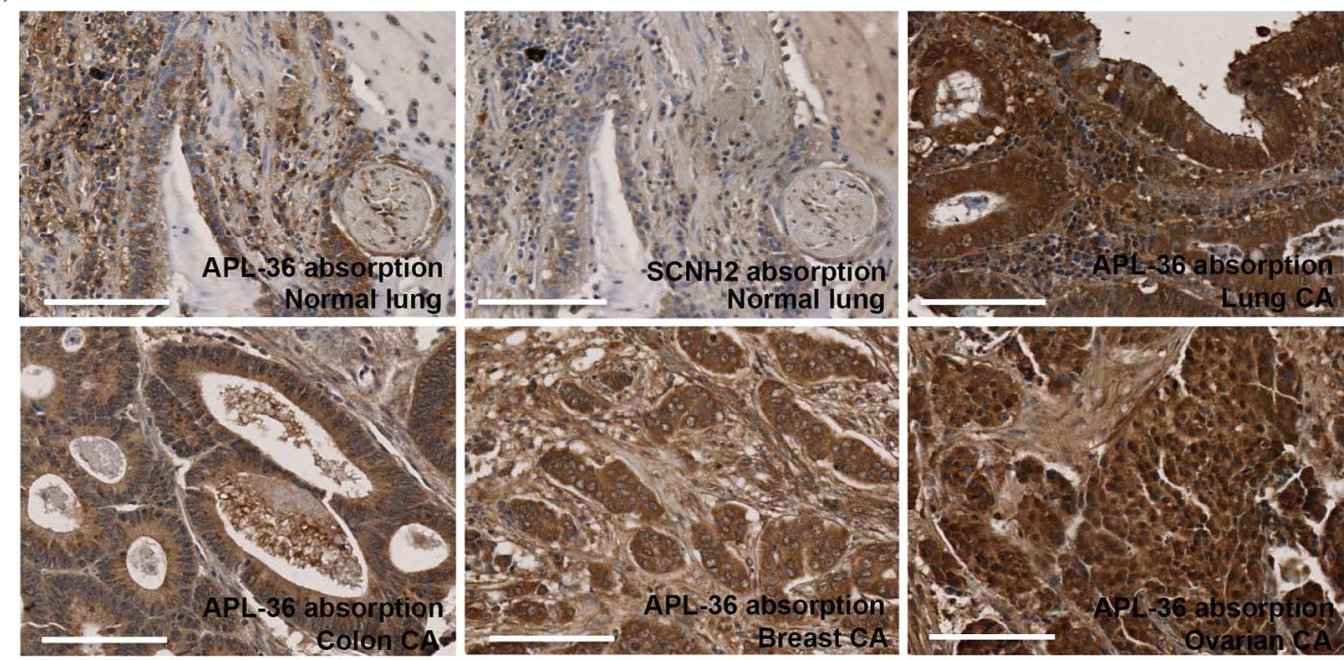

Figure 7. Identification of anatomical endogeneity of SCNH2 using IHC/IgGHIRS staining with/without APL-36 or SCNH2 absorption. (a) Human placenta tissue and mouse E17 embryonic tissues. Arrowheads indicate the stained trophoblasts. (b) Normal human lung and human tumor tissue arrays from pathological specimens. CA, cancer. Scale bar $=100 \mu \mathrm{M}$.

factors and have alternative C-terminal derivatives with either low or absent bioactivity [12-16], we assessed $\mathrm{SCNH} 2, \mathrm{SCOH}$, and SCGly derivatives for the trophic function. $\mathrm{SCNH} 2$ proved to be the only derivative with mitogenic activity, which confirmed the critical importance of an intact C-terminal amide residue for bioactivity and receptor recognition capability $[10,11]$.

APL-13 plays an important role in stimulating epith- elial cell growth, activating PI3K/Akt and p44/42 MAPK signaling pathways, modulating angiogenesis, regulating cell migration/invasion [37], underpinning metabolic and cardiovascular diseases, and normalizing tumor vasculature $[2,4-8]$. To investigate the bioactivities of $\mathrm{SCNH} 2$, we compared biological functions of $\mathrm{SCNH} 2$ and APL-13. SCNH2 and APL-13 have similar multi-functions regarding inducing cell growth, migration, invasion, 
and angiogenesis through the activation of PI3K/Akt and p44/42 MAPK signaling pathways. In addition, to blocking the effects of exogenous SCNH2, we developed a specific hyperimmune reagent IgGHIRS to SCNH2. Not surprisingly, IgGHIRS blocks not only the basal level but also all of the SCNH2-induced bioactivities. We found that the new peptide is far more potent at nanomolar and picomolar concentrations than APL-13 with regard to all of the performed functional assays and far more potent than VEGF-A regarding inducing in vivo angiogenesis and migration of HUVEC cells.

APL-13 activates the phosphorylation of PI3K/Akt and p44/42 MAPK signaling pathways via a Gi/oPCR, the APJ receptor [1-3]. We investigated whether $\mathrm{SCNH} 2$ was able to regulate the same signaling pathways and whether its regulation was mediated by the same receptor. Interestingly, we found that $\mathrm{SCNH} 2$ activated the PI3K/Akt and p44/42 MAPK signaling pathways through a receptor distinctly different from the one mediating APL-13 function. The PTX sensitivity assay has been used for Gi/o protein characterization and the APJ receptor is a PTX-sensitive Gi/o protein [19,28,30]. SCNH2 activation of PI3K/Akt and p44/42 MAPK signaling pathway is PTX resistant while being CTX sensitive (Gs component), which indicates that $\mathrm{SCNH} 2$ and APL-13 use different GPCRs.

Although SCNH2 was synthesized using a predicted amino acid sequence, its antibody (IgGHIRS) was able to specifically detect the endogenous expression of SCNH2 in normal human tissue, placenta, and tumors, and in mouse embryonic tissues. It is noteworthy that there is significant augmentation of $\mathrm{SCNH} 2$ expression in the mouse embryonic organs and in human tumors. Because there is a divergence in $\mathrm{SCNH} 2$ expression between viviparous and oviparous animals, we concluded that there was probably a significant evolutionary development in the implantation process given $\mathrm{SCNH} 2$ expression in fetal trophoblasts and its functional role in cell migration/invasion. Also, SCNH2 is able to execute its bioactivities at low nanomolar to picomolar concentrations. This suggests that SCNH2 could potentially play critical physiological roles in embryogenesis and carcinogenesis and may serve as a clinically relevant biomarker for certain malignant events.

\section{ACKNOWLEDGEMENTS}

We thank J. Prescott (Epitomics, Inc.) for assisting in the development of rabbit anti-SCNH2 reagents and for multiple discussions on assay design. We thank M. Shiue (Princeton Biomolecules) for synthesizing $\mathrm{SCNH} 2 / \mathrm{bSCNH} 2$ peptides and a helpful hint on peptide chemistry. We acknowledge D. Goldstein and S. Segal (National Cancer Institute) for establishing the NCI contract with Epitomics, Inc. A.C.A./R.F.N. grant support: NIH/NHLBI HL52585 and Merit Review Grant from Veterans Affairs Medical Research Services.

\section{AUTHOR CONTRIBUTIONS}

C.F., I.A., C.B., D.S.S., and F.C. designed the research. I.A. performed cell proliferation assays. C.B., N.H., and D.S.S. assessed phosphorylation of signaling pathways, time course analysis and PTX studies. C.F. performed migration/invasion assays and developed $\mathrm{bSCNH} 2 / \mathrm{SA}$ 488/FACS ligand binding assay. A.C.A. and R.F.N. ran the rat aortic ring assays and generated the quantitative data. L.A.F. and J.D.L. completed the CAM analysis for in vivo angiogenesis testing and generated the associated quantitative data. F.C. characterized the binding specificity of rabbit anti-SCHN2 reagents. W.G.S.-S. did the protein A purification and desalting of IgG-NRS/HIRS reagents. J.M., K.Y., S.M.H., C.F. and I.A. performed the tissue preparation and IHC staining. M.A. involved with assay design and experimental discussions. W.G.S.-S. board certified pathologist who critiqued IHC of human tumor tissue. C.B. and D.S.S. helped prepare the manuscript. C.F., I.A., and F.C. wrote the manuscript.

\section{REFERENCES}

[1] Tatemoto, K., et al. (1998) Isolation and characterization of a novel endogenous peptide ligand for the human APJ receptor. Biochemical and Biophysical Research Communications, 251, 471-476. doi:10.1006/bbrc.1998.9489

[2] Falcao-Pires, I., Ladeiras-Lopes, R. and Leite-Moreira, A.F. (2010) The apelinergic system: a promising therapeutic target. Expert opinion on therapeutic targets 14, 633-645. doi: $10.1517 / 14728221003752743$

[3] Volkoff, H. and Wyatt, J.L. (2009) Apelin in goldfish (Carassius auratus): Cloning, distribution and role in appetite regulation. Peptides, 30, 1434-1440.

doi:10.1016/j.peptides.2009.04.020

[4] Wang, G., et al. (2004) Apelin, a new enteric peptide: Localization in the gastrointestinal tract, ontogeny, and stimulation of gastric cell proliferation and of cholecystokinin secretion. Endocrinology, 145, 1342-1348. doi:10.1210/en.2003-1116

[5] Han, S., Wang, G., Qi, X., Lee, H.M., Englander, E.W. and Greeley Jr., G.H. (2008) A possible role for hypoxia-induced apelin expression in enteric cell proliferation. American Journal of Physiology. Regulatory, Integrative and Comparative Physiology, 294, R1832-1839. doi:10.1152/ajpregu.00083.2008

[6] Eyries, M., Siegfried, G., Ciumas, M., Montagne, K., Agrapart, M., Lebrin, F. and Soubrier, F. (2008) Hypoxia-induced apelin expression regulates endothelial cell proliferation and regenerative angiogenesis. Circulation Research, 103, 432-440. doi:10.1161/CIRCRESAHA.108.179333

[7] Del Toro, R., et al. (2010) Identification and functional analysis of endothelial tip cell-enriched genes. Blood, 116, 4025-4033. doi:10.1182/blood-2010-02-270819

[8] Kidoya, H., Kunii, N., Naito, H., Muramatsu, F., Oka- 
moto, Y., Nakayama, T. and Takakura, N. (2011) The apelin/APJ system induces maturation of the tumor vasculature and improves the efficiency of immune therapy. Oncogene, 31, 3254-3264.

[9] Tatemoto, K. and Mutt, V. (1980) Isolation of two novel candidate hormones using a chemical method for finding naturally occurring polypeptides. Nature, 285, 417-418. doi: $10.1038 / 285417 \mathrm{a} 0$

[10] Siegfried, J.M., Kasprzyk, P.G., Treston, A.M., Mulshine, J.L., Quinn, K.A. and Cuttitta, F. (1992) A mitogenic peptide amide encoded within the E peptide domain of the insulin-like growth factor IB prohormone. Proceedings of the National Academy of Sciences of the United States of America, 89, 8107-8111. doi:10.1073/pnas.89.17.8107

[11] Cuttitta, F. (1993) Peptide amidation: Signature of bioactivity. The Anatomical Record, 236, 87-93, 172-173. doi:10.1002/ar.1092360112

[12] Eguchi, S., et al. (1994) Structure-activity relationship of adrenomedullin, a novel vasodilatory peptide, in cultured rat vascular smooth muscle cells. Endocrinology, 135, 2454-2458. doi:10.1210/en.135.6.2454

[13] Kitamura, K., Kato, J., Kawamoto, M., Tanaka, M., Chino, N., Kangawa, K. and Eto, T. (1998) The intermediate form of glycine-extended adrenomedullin is the major circulating molecular form in human plasma. Biochemical and Biophysical Research Communications, 244, 551-555. doi:10.1006/bbrc. 1998.8310

[14] Cornish, J., Callon, K.E., Coy, D.H., Jiang, N.Y., Xiao, L., Cooper, G.J. and Reid, I.R. (1997) Adrenomedullin is a potent stimulator of osteoblastic activity in vitro and in vivo. The American Journal of Physiology, 273, E1113E1120.

[15] Shichiri, M., Fukai, N., Ozawa, N., Iwasaki, H. and Hirata, Y. (2003) Adrenomedullin is an autocrine/paracrine growth factor for rat vascular smooth muscle cells. Regulatory Peptides, 112, 167-173. doi:10.1016/S0167-0115(03)00036-3

[16] Martinez, A., Miller, M.J., Unsworth, E.J., Siegfried, J.M. and Cuttitta, F. (1995) Expression of adrenomedullin in normal human lung and in pulmonary tumors. Endocrinology, 136, 4099-4105. doi:10.1210/en.136.9.4099

[17] Bianco, C., et al. (2005) Role of human cripto-1 in tumor angiogenesis. Journal of the National Cancer Institute, 97, 132-141. doi:10.1093/jnci/dji011

[18] Chaturvedi, K. and Sarkar, D.K. (2005) Role of protein kinase C-Ras-MAPK p44/42 in ethanol and transforming growth factor-beta3-induced basic fibroblast growth factor release from folliculostellate cells. The Journal of Pharmacology and Experimental Therapeutics, 314, 1346-1352. doi:10.1124/jpet.105.088302

[19] Masri, B., Lahlou, H., Mazarguil, H., Knibiehler, B. and Audigier, Y. (2002) Apelin (65-77) activates extracellular signal-regulated kinases via a PTX-sensitive G protein. Biochemical and Biophysical Research Communications, 290, 539-545. doi:10.1006/bbrc.2001.6230

[20] Aplin, A.C., Fogel, E., Zorzi, P. and Nicosia, R.F. (2008) The aortic ring model of angiogenesis. Methods in Enzy- mology, 443, 119-136. doi:10.1016/S0076-6879(08)02007-7

[21] Zijlstra, A., Seandel, M., Kupriyanova, T.A., Partridge, J.J., Madsen, M.A., Hahn-Dantona, E.A., Quigley, J.P. and Deryugina, E.I. (2006) Proangiogenic role of neutrophil-like inflammatory heterophils during neovascularization induced by growth factors and human tumor cells. Blood, 107, 317-327. doi:10.1182/blood-2005-04-1458

[22] Dokholyan, N.V. and Shakhnovich, E.I. (2001) Understanding hierarchical protein evolution from first principles. Journal of Molecular Biology, 312, 289-307. doi:10.1006/jmbi.2001.4949

[23] Greten, F.R., Eckmann, L., Greten, T.F., Park, J.M., Li, Z.W., Egan, L.J., Kagnoff, M.F. and Karin, M. (2004) IKKbeta links inflammation and tumorigenesis in a mouse model of colitis-associated cancer. Cell, 118 , 285-296. doi:10.1016/j.cell.2004.07.013

[24] Folkman, J. (1971) Tumor angiogenesis: Therapeutic implications. The New England Journal of Medicine, 285, 1182-1186. doi:10.1056/NEJM197111182852108

[25] Nanus, D.M., Schmitz-Drager, B.J., Motzer, R.J., Lee, A.C., Vlamis, V., Cordon-Cardo, C., Albino, A.P. and Reuter, V.E. (1993) Expression of basic fibroblast growth factor in primary human renal tumors: Correlation with poor survival. Journal of the National Cancer Institute, 85, 1597-1599. doi:10.1093/jnci/85.19.1597

[26] Tang, S.Y., et al. (2007) Apelin stimulates proliferation and suppresses apoptosis of mouse osteoblastic cell line MC3T3-E1 via JNK and PI3-K/Akt signaling pathways. Peptides, 28, 708-718. doi:10.1016/i.peptides.2006.10.005

[27] Simpkin, J.C., Yellon, D.M., Davidson, S.M., Lim, S.Y., Wynne, A.M. and Smith, C.C. (2007) Apelin-13 and apelin-36 exhibit direct cardioprotective activity against ischemia-reperfusion injury. Basic Research in Cardiology, 102, 518-528. doi:10.1007/s00395-007-0671-2

[28] Fields, T.A. and Casey, P.J. (1997) Signalling functions and biochemical properties of pertussis toxin-resistant G-proteins. The Biochemical Journal, 321, 561-571.

[29] Gilman, A.G. (1987) G proteins: Transducers of receptor-generated signals. Annual Review of Biochemistry, 56, 615-649. doi:10.1146/annurev.bi.56.070187.003151

[30] Goode, T.L. and Raffa, R.B. (1997) An examination of the relationship between mu-opioid antinociceptive efficacy and G-protein coupling using pertussis and cholera toxins. Life Sciences, 60, PL107-113. doi:10.1016/S0024-3205(96)00684-4

[31] Naruse, K., Innes, B.A., Bulmer, J.N., Robson, S.C., Searle, R.F. and Lash, G.E. (2010) Secretion of cytokines by villous cytotrophoblast and extravillous trophoblast in the first trimester of human pregnancy. Journal of Reproductive Immunology, 86, 148-150. doi:10.1016/j.jri.2010.04.004

[32] Plaisier, M. (2011) Decidualisation and angiogenesis. Best practice \& research. Clinical Obstetrics \& Gynaecology, 25, 259-271. doi:10.1016/j.bpobgyn.2010.10.011

[33] Yotsumoto, S., Shimada, T., Cui, C.Y., Nakashima, H., Fujiwara, H. and Ko, M.S. (1998) Expression of 
adrenomedullin, a hypotensive peptide, in the trophoblast giant cells at the embryo implantation site in mouse. Developmental Biology, 203, 264-275. doi:10.1006/dbio.1998.9073

[34] Montuenga, L.M., Martinez, A., Miller, M.J., Unsworth, E.J. and Cuttitta, F. (1997) Expression of adrenomedullin and its receptor during embryogenesis suggests autocrine or paracrine modes of action. Endocrinology, 138, 440451. doi:10.1210/en.138.1.440

[35] Zhang, J., Zheng, M., Eipper, B.A. and Pintar, J.E. (1997) Embryonic and uterine expression patterns of peptidylglycine alpha-amidating monooxygenase transcripts sug- gest a widespread role for amidated peptides in development. Developmental Biology, 192, 375-391.

doi:10.1006/dbio.1997.8750

[36] Berta, J., et al. (2010) Apelin expression in human non-small cell lung cancer: Role in angiogenesis and prognosis. Journal of Thoracic Oncology: Official Publication of the International Association for the Study of Lung Cancer, 5, 1120-1129.

[37] Heo, K., et al. (2012) Hypoxia-induced up-regulation of apelin is associated with a poor prognosis in oral squamous cell carcinoma patients. Oral Oncology, 48, 500-5006. doi:10.1016/j.oraloncology.2011.12.015 